\title{
Combination treatment of neuropathic pain: Danish expert recommendations based on a Delphi process
}

This article was published in the following Dove Press journal: Journal of Pain Research

26 June 2017

Number of times this article has been viewed

\author{
Jakob Vormstrup Holbech' \\ Anne Jung ${ }^{2}$ \\ Torsten Jonsson ${ }^{3}$ \\ Mette Wanning ${ }^{4}$ \\ Claus Bredahl ${ }^{5}$ \\ Flemming W Bach ${ }^{6}$ \\ 'Department of Neurology, Odense \\ University Hospital, Odense, \\ ${ }^{2}$ Medicinsk Fælles Ambulatorium, \\ Holbaek Hospital, ${ }^{3}$ Aleris-Hamlet \\ Hospitaler Ringsted, ${ }^{4}$ The Private \\ Pain Clinic, Herlev, ${ }^{5} \mathrm{Clinic}$ Acute \\ Orthopedic Surgical Anesthesia \\ Section, Aalborg Universitetshospital, \\ Aalborg, ${ }^{6}$ Department of Neurology, \\ Aarhus University Hospital, Aarhus, \\ Denmark
}

Background: Current Danish treatment algorithms for pharmacological treatment of neuropathic pain $(\mathrm{NeP})$ are tricyclic antidepressants (TCA), gabapentin and pregabalin as first-line treatment for the most common NeP conditions. Many patients have insufficient pain relief on monotherapy, but combination therapy had not been included in guidelines until recently. Based on clinical empiricism and scientific evidence, a Delphi consensus process provided a consolidated guidance on pharmacological combination treatment of $\mathrm{NeP}$.

Methods: A two-round virtual internet-based Delphi process with 6 Danish pain specialists was undertaken. In the first round, questions were answered individually and anonymously, whereas in the second round, the panel openly discussed first round's summary of outcomes. Combinations of pharmacological pain treatments, that is, pregabalin/gabapentin, TCAs, serotonin-norepinephrine reuptake inhibitors (SNRIs), selective serotonin reuptake inhibitors, opioids, other antiepileptics and cutaneous patches, were assessed based on both scientific and clinical practice experiences. The Centers for Disease Control and Prevention (CDC) grading system was used for evidence rating. Results: Combination of pregabalin/gabapentin with TCA is useful in patients who do not gain sufficient pain relief or tolerate either drug in high doses, or to improve sleep disturbance. Also, combination of pregabalin/gabapentin and SNRIs is reasonably well documented and experienced by some experts to result in sufficient pain relief and fewer side effects than monotherapy. Good evidence on efficacy was found for the combination of pregabalin/gabapentin or TCAs and opioids, which was also frequently used in clinical practice. The evidence for combining TCAs and SNRIs is insufficient, although sometimes used in clinical practice despite the risk of serotonin syndrome. For localized NeP, combination therapy with cutaneous patches should be considered. There was insufficient scientific evidence for any pharmacologic combination therapies with selective serotonin reuptake inhibitors - as well as for other potential combinations. Conclusions: The study revealed that combination therapy is widely used in clinical practice and supported by some scientific evidence. However, further studies are needed.

Keywords: neuropathic pain, combination therapy, Delphi panel, recommendations, CDC grading system, clinical practice

\section{Background}

Neuropathic pain $(\mathrm{NeP})$ is triggered by a lesion or a disease affecting the somatosensory nervous system that alters its structure and function, so that pain occurs spontaneously and responses to noxious and innocuous stimuli are pathologically amplified. ${ }^{1}$ Peripheral causes of $\mathrm{NeP}$ are for example, polyneuropathy, postherpetic neuralgia, postoperative pain, and posttraumatic neuralgia, while causes of central NeP are spinal cord injuries, stroke, and so on. The current Danish treatment algorithms ${ }^{2-5}$ are
Correspondence: Jakob Vormstrup Holbech

Department of Neurology, Odense University Hospital, Søndre Boulevard 29, DK-5000 Odense, Denmark Email Holbech@dadlnet.dk 
founded on the evidence-based recommendations provided by the international pain societies. The European guidelines for the pharmacological treatment of NeP issued by the European Federation of Neurological Societies recommend tricyclic antidepressants (TCA), gabapentin, and pregabalin as first-line treatment for the most common NeP conditions, including diabetic neuropathy where serotonin-noradrenaline reuptake inhibitors (SNRI) are also recommended. ${ }^{6}$ Finnerup et al, recently revised the worldwide applied NeP pharmacotherapy recommendations from the Special Interest Group on neuropathic pain concluding that there was a strong Grades of Recommendation Assessment, Development and Evaluation (GRADE) recommendation for use and proposal as first-line treatment for TCA, SNRI, pregabalin, and gabapentin. ${ }^{7}$

Combination therapy, that is, the combination of different pharmacological treatments, has not been a part of guidelines until recently. The combination of pregabalin or gabapentin with either TCAs or SNRIs is now mentioned as a treatment option if a patient cannot tolerate high-dose monotherapy. ${ }^{7}$ The idea of combination therapy using two drugs with different mechanisms of action is of great interest, as it is widely acknowledged that many patients have insufficient pain relief on monotherapy with the currently used drugs. Furthermore, the drugs used for treatment of NeP have severe dose-dependent side effects and tolerability issues, that often lead to discontinuation of high-dose monotherapies. Other fields of medicine apply combination therapy so as to avoid high-dose monotherapy such as for example, treatment of hypertension or diabetes. In a similar fashion, pain medicine could benefit from using lower dose combination therapies with different mechanisms of action. An example could be a moderate dose of a drug reducing calcium influx (pregabalin or gabapentin) combined with a moderate dose of a drug inhibiting the serotonin and noradrenaline reuptake (duloxetine).

In clinical practice, patients with $\mathrm{NeP}$ are apparently often treated with combination therapy. Furthermore, in the literature, some evidence exists on the use of different combinations of pharmacological therapies. Based on this existing clinical empiricism, daily clinical practice, and the available scientific evidence in the literature on pharmacological combination therapy for $\mathrm{NeP}$, a Delphi consensus process with 6 Danish pain specialists was established. The Delphi process was chosen because it has a structured approach that aggregates diverse opinions from experts having knowledge within the area of interest that is required for decision making. Participants were anonymous during the process. This prevented the authority or personality of some participants from dominating others in the process, and allowed free expression of opinions. Hence, it is a comprehensive approach when aiming at consensus within a specific area of expertise. The purpose of the Delphi panel and process was to provide a consolidated guidance on pharmacological combination treatment of NeP, based on the assessment of the quality of existing clinical data and clinical empiricism.

The present article summarizes the Delphi method and the recommendations put forward by the 6 Danish Delphi panelists with respect to combination therapy for the management of NeP.

\section{Methods}

Based on the available scientific evidence and daily clinical experience, the Delphi panel, consisting of six Danish pain specialists, discussed the optimal pharmacological combinations for NeP management. This discussion followed the methods of a 2-round Delphi process, as this method was deemed best suited for reaching consensus. The process was run virtually, that is, solely conducted via the internet with no physical meeting between the participants, but constant virtual access to all documents. The method allowed free and anonymous speech without interruptions and submission of responses at the convenience of the participants, as well as the ability to see and comment upon the other participants' answers. The participation in the study was based on informed consent from each of the 6 pain specialists, who also signed a contract with Pfizer PFE regarding the complete Delphi process. In Denmark, there are no requirements for approval by authorities for this type of study. In the first round, each member of the Delphi panel answered all questions individually and anonymously. After the first round, Pfizer compiled the ratings, and the participants received a summary of the outcome of the first round before attending the second round. This allowed the participants to review their own answers and comments relative to those of the other participants before reviewing all possible combinations again in the second round. In this round, the participants only needed to answer the questions to which they had further input. A final summary report was made after the second round of the Delphi process.

Basically, the Delphi panel had to answer 2 overall questions (and some associated sub-questions) regarding pharmacological combination pain treatment of NeP:

1. Could the following combination treatments be considered for treatment of $\mathrm{NeP}$ and in what doses and regimens? 
2. For which diagnosis should combination treatments be considered and how?

a. Peripheral NeP (i.e., polyneuropathies, postoperative pain, posttraumatic neuralgia, postherpetic neuralgia)

b. Central NeP (i.e., stroke, spinal cord injuries) should combination treatments be considered and how?

Although peripheral as well as central NeP were in scope, it should be noted that evidence is almost exclusively within peripheral NeP conditions. However, findings in peripheral $\mathrm{NeP}$ are generally considered also to be applicable for central NeP.

The potential pharmacological pain treatments that the Delphi panel had to assess in terms of combination therapy were: pregabalin/gabapentin, TCAs, SNRIs, selective serotonin reuptake inhibitors (SSRIs), opioids, other antiepileptics and cutaneous patches.

For each of these combined pharmaceutical pain treatment options; all combinations with the other pharmaceutical pain therapies were considered and the quality of evidence and strength of recommendation of the specific combination was rated. Where no or limited scientific evidence was available, the experts discussed the combination therapy from their clinical experiences. For each of the combination therapies, the level of evidence is given.

Most of the included literature was provided to the expert panel 2 weeks before the Delphi process began. However, literature could be added during the process at the will of any of the experts. The literature provided upfront was a result of comprehensive literature searches in EMBASE and MEDLINE using the search terms; combination therapy, combination treatment, $\mathrm{NeP}$ for both central and peripheral neuropathic pain. Only literature in Danish or English was included. In order to have a more acceptable number of articles for the process, the comprehensive Cochrane review on combination therapy from $2012^{8}$ was included and relevant clinical studies published after 2012 was found and included.

The rating of the evidence is based upon the Centers for Disease Control and Prevention (CDC) grading system presented below in Table 1. The CDC grading system is developed by the Infectious Diseases Society of America US Public Health Service and chosen because this evidence grading system is a relatively simple and well-suited system for ranking recommendations in clinical guidelines. ${ }^{9}$ Also, in the absence of sufficient evidence to build a clear conclusion, final recommendations are based on the majority of panel experts' opinion. Because of the sparse literature on combination therapy, it was not possible to apply the more comprehensive GRADE system.

A combination of two types of pain pharmacotherapy with a rating of "I+A" in this system has the highest rating, as it indicates that there is at least one or more properly randomized controlled trial (RCT) as well as strong evidence for efficacy and substantial clinical benefit. In this case, the combination therapy would be highly recommended. On the other hand, a rating of "III+E" implies there is strong evidence against the combination therapy being efficacious or that it results in adverse outcomes, based on expert opinions only (no clinical trials). Such a pharmacologic combination would never be recommended.

\section{Results}

Following the two rounds in the Delphi panel and process, all potential combinations of each of the pharmacological $\mathrm{NeP}$ treatment therapies were assessed, discussed from a

Table I Centers for Disease Control and Prevention grading system on quality of evidence and strength of recommendation

Quality of evidence

Evidence from $\geq$ I properly randomized controlled trial

Evidence from $\geq$ I well designed clinical trial, without randomization: from cohort or case-control analytic studies (preferable from $>$ I center); from multiple time-series studies; or from dramatic results from uncontrolled experiments

Evidence from opinions of respected authorities, based on clinical experience, descriptive studies or reports of expert committees

\section{Strength of recommendation}

Strong evidence for efficacy and substantial clinical benefit; strongly recommended/good evidence to support a recommendation for or against use

Strong or moderate evidence for efficacy, but only limited clinical benefit; generally recommended/moderate evidence to support a recommendation for or against use

Insufficient evidence for efficacy; or efficacy does not outweigh possible adverse consequences (e.g., drug toxicity or interactions) or cost of chemoprophylaxis or alternative approaches; optional/poor evidence to support a recommendation

Moderate evidence against efficacy or for adverse outcome; generally not recommended

Strong evidence against efficacy or of adverse outcome; never

recommended 
mechanistic point of view and rated. The ratings and the recommendations for each of the potential combination therapies are discussed below.

\section{Combination therapy with pregabalin/ gabapentin}

Table 2 presents the Delphi panel's rating of the available scientific and clinical evidence for combination therapy with pregabalin/gabapentin.

The combination of pregabalin/gabapentin with TCA is useful in patients who do not tolerate either drug in high doses or who have insufficient pain relief on monotherapy. Gilron et $\mathrm{al}^{10}$ (2400 mg gabapentin plus $50 \mathrm{mg}$ TCA) and Holbech et $\mathrm{al}^{11}$ (300 $\mathrm{mg}$ pregabalin plus $75 \mathrm{mg}$ TCA) studied this combination in RCTs in patients with peripheral NeP. Both studies showed a significant effect of the combination therapy over monotherapy. This combination is also useful to improve sleep disturbance due to the sedative effect from TCA.

The Delphi panel assessed the combination of pregabalin/ gabapentin and SNRIs as being reasonably well documented (CDC rating I/II $+\mathrm{B} / \mathrm{C}$ ). A study by Tesfaye et al, found no significant effect of the moderate-dose combination $(300 \mathrm{mg}$ pregabalin plus $60 \mathrm{mg}$ duloxetine) therapy on peripheral $\mathrm{NeP}$ compared with high-dose monotherapy (600 $\mathrm{mg}$ pregabalin or $120 \mathrm{mg}$ duloxetine). ${ }^{12}$ However, this combination therapy was considered to be potentially effective, safe, and well tolerated and if the study had been designed as combination vs. identical doses of monotherapy, one could assume that the combined effect would have been significantly higher.
Furthermore, adverse event frequencies were generally lower during combination therapy. The study by Tanenberg et $\mathrm{al}^{13}$ studied a ( $\geq 900 \mathrm{mg}$ gabapentin plus $60 \mathrm{mg}$ duloxetine) combination and found that insomnia was more frequent with duloxetine than duloxetine plus gabapentin and nausea, hyperhidrosis, decreased appetite, and vomiting more frequent with duloxetine plus gabapentin than with pregabalin $(300 \mathrm{mg})$. There was significant difference in pain relief on duloxetine plus gabapentin vs duloxetine or pregabalin monotherapies. In parallel, some of the experts concluded that in their clinical experience, moderate-dose pregabalin/gabapentin and SNRI combination therapy results in sufficient pain relief and fewer side effects compared with monotherapy.

There was insufficient evidence to support a recommendation for the combination of pregabalin/gabapentin and SSRIs (CDC rating III $+\mathrm{C}$ ) (Table 2). SSRIs have at best moderate effect (e.g., Sindrup et $\mathrm{al}^{14}$ and Otto et $\mathrm{al}{ }^{15}$ ), but there are also negative trials. All trials are for peripheral NeP. Because of poor efficacy, SSRIs are not relevant in the treatment of NeP, except for patients already on SSRI for other diagnoses like depression or anxiety, in which case pregabalin or gabapentin may be added.

Good evidence on efficacy was found for the combination of pregabalin/gabapentin and opioids in RCTs by Gilron et $\mathrm{a}^{16}$ ( $2400 \mathrm{mg}$ gabapentin plus $60 \mathrm{mg}$ morphine), Hanna et $\mathrm{al}^{17}$ (flexible moderate-dose gabapentin plus flexible moderate-dose oxycodone) and by Caraceni et a ${ }^{18}$ (fix-dose oxycodone plus moderate flexible-dose gabapentin [maximum $1800 \mathrm{mg}]$ ) in peripheral NeP. This combination is also

Table 2 Combination therapy with pregabalin or gabapentin

\begin{tabular}{|c|c|c|c|}
\hline $\begin{array}{l}\text { Pregabalin/gabapentin } \\
\text { combined with: }\end{array}$ & $\begin{array}{l}\text { CDC rating of } \\
\text { scientific evidence }\end{array}$ & $\begin{array}{l}\text { RCTs testing the } \\
\text { combination }\end{array}$ & Clinical practice experience concerning combinations \\
\hline TCAs & $\mathrm{I}+\mathrm{A}$ & $\begin{array}{l}\text { Gilron et } \mathrm{al}^{10} \text { and Holbech } \\
\text { et al"' }\end{array}$ & $\begin{array}{l}\text { Combination well documented. Most with peripheral NeP. Useful } \\
\text { combination for patients who do not tolerate either drug in larger } \\
\text { doses, as well as sedative effect from TCA to improve sleep } \\
\text { disturbance }\end{array}$ \\
\hline SNRIs & $\mathrm{I} / \mathrm{II}+\mathrm{B} / \mathrm{C}$ & $\begin{array}{l}\text { Tesfaye et al }{ }^{12} \text { and } \\
\text { Tannenberg et al }{ }^{13}\end{array}$ & $\begin{array}{l}\text { Combination reasonably well documented. Used by some of the } \\
\text { experts with good effect and fewer side effects than with TCA }\end{array}$ \\
\hline SSRIs & $\mathrm{III}+\mathrm{C}$ & None & $\begin{array}{l}\text { Insufficient evidence available. SSRIs not relevant in the treatment } \\
\text { of } \mathrm{NeP}\end{array}$ \\
\hline Opioids ${ }^{a}$ & $I+B$ & $\begin{array}{l}\text { Gilron et al }{ }^{16} \text {, Hanna et al }{ }^{17} \\
\text { and Caraceni et al }\left.\right|^{18}\end{array}$ & $\begin{array}{l}\text { Good evidence to support combination therapy. Frequently used } \\
\text { in daily clinical practice }\end{array}$ \\
\hline $\begin{array}{l}\text { Other antiepileptics }{ }^{\mathrm{b}}(\mathrm{Na}+ \\
\text { channel blockers) }\end{array}$ & $\mathrm{C}$ & None & $\begin{array}{l}\text { Insufficient evidence available. Combination could work in theory } \\
\text { due to different mechanisms of action. Limited clinical experience }\end{array}$ \\
\hline Cutaneous patches & $\mathrm{I}+\mathrm{A} / \mathrm{C}$ & $\begin{array}{l}\text { Casale et al, }{ }^{19} \text { Meier et } \mathrm{al}^{20} \\
\text { and Irving et al }{ }^{21}\end{array}$ & $\begin{array}{l}\text { Mixed evidence and results for localized NeP. Patches add-on to } \\
\text { oral therapy are used by some experts with good effect }\end{array}$ \\
\hline Others & C & None & Insufficient evidence and clinical practice available \\
\hline
\end{tabular}

Notes: alncluding synthetics. 'Mainly sodium channel blockers, but also multiple mode of action drugs (valproic acid and topiramate).

Abbreviations: CDC, Centers for Disease Control and Prevention; NeP, neuropathic pain; RCTs, randomized controlled trials; SNRIs, serotonin-noradrenaline reuptake inhibitors; SSRIs, selective serotonin reuptake inhibitors; TCAs, tricyclic antidepressants. 
frequently used in clinical practice ( $\mathrm{CDC}$ rating $\mathrm{I}+\mathrm{B}$ ). Based on clinical experience, it was commented that the combination therapy results in increased effect, but with simultaneous increase in side effects relative to monotherapies. Although a class effect of opioids is often described, clinical experience shows a difference of effect between the opioids. Therefore, the opioid to select may depend on the single patient to treat and whether opioid therapy is already ongoing, that is, patients can react very differently on various opioids.

Insufficient scientific evidence was found by the Delphi panel for the combination of pregabalin/gabapentin and other antiepileptics (Table 2). In theory, the combination could be effective due to different mechanisms of action. However, neither sodium channel blockers such as lamotrigine nor multiple modes of action drugs such as topiramate have any certain role in the treatment of $\mathrm{NeP}^{7}$ In general, this combination was seldom used by the experts.

No clear consensus was reached for the combination of pregabalin/gabapentin and cutaneous patches as studies are add-on and not combination studies (Table 2). Casale et $\mathrm{al}^{19}$ and Meier et $\mathrm{al}^{20}$ have studied lidocaine patches in clinical trials as add-on treatment to oral therapy, including pregabalin/gabapentin, with good effect and hardly any side effects. Other trials, for example, Irving et al, ${ }^{21}$ added capsaicin patches to chronic pain medications, such as anticonvulsants and found also a favorable response. Haanpää and Hietaharju ${ }^{22}$ advocate for combining a locally acting preparation with a systemic drug for treatment of postherpetic neuralgia. The advisors gave mixed responses: good and insufficient evidence for localized NeP, which is the indication for patches. Overall, experience in clinical practice is that cutaneous patches can be combined with all types of oral therapy in patients who are suitable for local treatment.

Finally, the Delphi panel found insufficient scientific evidence for the combination of pregabalin/gabapentin and other pharmacological options like nonsteroidal antiinflammatory drugs and acetaminophen than those described above (Table 2).

\section{Combination therapy with TCAs}

Table 3 below presents the rating of the scientific evidence and clinical experience with combinations with TCAs. The combination therapy with pregabalin/gabapentin was described in the previous section and shown in Table 2.

The Delphi panel agreed that the evidence for the combination of TCAs and SNRIs was insufficient (CDC rating C) (Table 3). Although this combination is sometimes used in clinical practice, the overlapping side effect profile and the risk of serotonin syndrome makes this combination less useful.

For the combination of TCAs and SSRIs, moderate evidence was found against its use and the Delphi panel would not recommend it (CDC rating $\mathrm{D})$. This combination imposes a high risk of serotonin syndrome.

The majority of the Delphi panel found that there is good evidence for the combination of TCAs and opioids (CDC rating $\mathrm{I}+\mathrm{B}$ ) (Table 3$)$. The scientific evidence is, however, divergent, dependent on the type of NeP. Mercadante et $\mathrm{al}^{23}$ and Khoromi et $\mathrm{al}^{24}$ found no additional effect of the combination for neuropathic cancer and lumbar pain, whereas in $\mathrm{NeP}$ of mixed causes, Gilron et $\mathrm{al}^{25}$ showed a favorable effect (flexible maximum tolerable dose [MTD] $100 \mathrm{mg}$ morphine per day plus flexible MTD $100 \mathrm{mg}$ nortriptyline

Table 3 Combination therapy with TCAs

\begin{tabular}{|c|c|c|c|}
\hline TCAs combined with: & $\begin{array}{l}\text { CDC rating of } \\
\text { scientific evidence }\end{array}$ & $\begin{array}{l}\text { RCTs testing the } \\
\text { combination }\end{array}$ & Clinical practice experience concerning combinations \\
\hline SNRIs & $\mathrm{C}$ & None & $\begin{array}{l}\text { Insufficient evidence available. Overlap in mechanism of action makes } \\
\text { the combination less useful in theory }\end{array}$ \\
\hline SSRIs & $\mathrm{D}$ & None & Moderate evidence against the use of the combination \\
\hline Opioids ${ }^{b}$ & $\mathrm{I}+\mathrm{B}$ & $\begin{array}{l}\text { Mercadante et al, }{ }^{23} \\
\text { Khoromi et } \mathrm{al}^{24} \text { and } \\
\text { Gilron et } \mathrm{al}^{25}\end{array}$ & $\begin{array}{l}\text { Good evidence to support this combination. Frequently used in daily } \\
\text { clinical practice }\end{array}$ \\
\hline $\begin{array}{l}\text { Other antiepileptics } \\
(\mathrm{Na}+\text { channel blockers) }\end{array}$ & $\mathrm{C}$ & None & $\begin{array}{l}\text { Insufficient evidence available. Combination could work in theory due to } \\
\text { different mechanisms of action. Limited clinical experience }\end{array}$ \\
\hline Cutaneous patches & $\mathrm{A} / \mathrm{C}$ & None & $\begin{array}{l}\text { Insufficient evidence to support a recommendation for this combination } \\
\text { therapy. Combination could work in theory }\end{array}$ \\
\hline Others & C & None & Insufficient evidence to support a recommendation for this \\
\hline
\end{tabular}

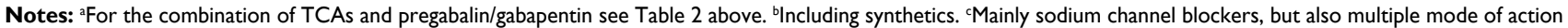
drugs (valproic acid and topiramate).

Abbreviations: CDC, Centers for Disease Control and Prevention; RCTs, randomized controlled trials; SNRIs, serotonin-noradrenaline reuptake inhibitors; TCAs, tricyclic antidepressants. 
per day compared with monotherapy with each drug). Mean MTD dose (mg \pm SEM) of nortriptyline was $83.9 \pm 3.2 \mathrm{mg}$ as monotherapy versus $60.2 \pm 4.6 \mathrm{mg}$ in combination. Mean MTD dose of morphine was $65.4 \pm 4.3 \mathrm{mg}$ as monotherapy versus $60.2 \pm 4.6 \mathrm{mg}$ in combination. The combination also led to fewer side effects than high-dose monotherapy. The combination of TCAs and opioids is frequently used by the experts.

For the combinations of TCAs and other antiepileptics, there is insufficient evidence to support a recommendation (CDC rating C) (Table 3). However, a combination of TCAs and a sodium channel blocker such as lamotrigine may be considered as a last resort for treatment of $\mathrm{NeP}$.

Most experts (4 out of 6 ) in the panel found the evidence to be insufficient for the combination of TCAs and cutaneous patches; whereas others found it good (CDC rating A/C) even though no evidence from RCTs could be found. TCAs and patches with lidocaine/capsaicin have been used with favorable response and no increase in side effects by the experts.

The Delphi panel agreed that there is insufficient evidence to support a recommendation for the combination of TCAs and other drugs such as fluphenazine. The combination of TCAs and tramadol (CDC rating $\mathrm{C}$ ) was an exception, as it has been used with good clinical experiences by few experts in the panel.

The Delphi panel underlines that caution is advised for use of TCA in the elderly because of anticholinergic side effects and cardiotoxicity.

\section{Combination therapy with SNRIs}

The ratings for the combinations of SNRI and other drugs apart from pregabalin/gabapentin or TCAs, are presented in Table 4 below.

Moderate evidence was found against the use of the combination SNRI and SSRI, which is why it is not recommended (CDC rating D). Also, high risk of serotonin syndrome makes the combination inapplicable.

For all the other described combinations with SNRIs in Table 4, the panel agreed that there is insufficient evidence to support a recommendation for such a combination (CDC rating $\mathrm{C}$ ). With respect to the combination of SNRIs and other antiepileptics, few practical experiences are available.

\section{Combination therapy with SSRIs}

The Delphi panel concluded that there was insufficient scientific evidence to support a recommendation for any pharmacologic combination therapies with SSRIs. CDC rating was $\mathrm{C}$ for all possible combinations apart from combination with TCAs, which was rated D due to the high risk of serotonin syndrome with this combination. Basically, the panel agreed that SSRIs have no role in the treatment of NeP.

\section{Combination therapy with opioids}

The best evidence for the use of opioids in combination therapy is with pregabalin/gabapentin (Table 2) and TCAs (Table 3) (CDC rating I+B). There is insufficient evidence to support recommendations for combination of opioids with any of the other pharmacologic treatments - SNRIs, SSRIs, other antiepileptics (NA + channel blockers), cutaneous patches, and other pain pharmacological therapies (CDC rating C). Due to the regular use of opioids in pain management, there is some clinical experience with opioid combination therapy. This is mainly due to the fact that patients cannot be tapered off the opioid completely. Often patients are on opioids because all other monotherapy options are without effect. Opioids are also combined with other pain pharmaceuticals like ketamine $(10 \mathrm{mg} \times 3)$ in some patients with peripheral $\mathrm{NeP}$ and/or poor responders to first- and second-line drugs. In general, it would be beneficial, if the effect of opioids was not seen as a class effect, as clinical experience shows that there are meaningful differences between opioids within classes - dependent on the patient. For the multi-morbid frail old patients, who do not tolerate the usual first-line drugs for NeP, there are good clinical experiences with treatment with the dual-action agonist (combined opioid-agonist/ noradrenaline-re-uptake antagonist) drug tapentadol. Another

Table 4 Combination therapy with SNRIs ${ }^{a}$

\begin{tabular}{|c|c|c|c|}
\hline SNRIs combined with: & $\begin{array}{l}\text { CDC rating of } \\
\text { scientific evidence }\end{array}$ & $\begin{array}{l}\text { RCTs testing the } \\
\text { combination }\end{array}$ & Clinical practice experience concerning combinations \\
\hline SSRIs & $\mathrm{D}$ & None & Moderate evidence against the use of the combination. \\
\hline Opiods ${ }^{b}$ & C & None & $\begin{array}{l}\text { Insufficient evidence available. Combination could work in theory } \\
\text { due to different mechanisms of action. }\end{array}$ \\
\hline $\begin{array}{l}\text { Other antiepileptics } \\
(\mathrm{Na}+\text { channel blockers })\end{array}$ & C & None & $\begin{array}{l}\text { Insufficient evidence available. Most experts have no experience with } \\
\text { the combination. Combination could work in theory. }\end{array}$ \\
\hline Cutaneous patches & C & None & Insufficient evidence available. Combination could work in theory. \\
\hline Others & C & None & Insufficient evidence to support a recommendation for this. \\
\hline
\end{tabular}


possibility, when looking at interactions, side effects, polypharmacy and compliance is buprenorphine patch combined with duloxetine, both in small doses.

When discussing opioids in general, the Delphi panel noticed that these drugs should be considered a last option in the treatment of chronic NeP of any cause, because of the risk of misuse, addiction and higher mortality related to these drugs. ${ }^{7}$

\section{Combination therapy with other antiepileptics}

The Delphi panel of experts concluded that there was no scientific evidence for combining any other antiepileptic with any other pharmacological therapies for $\mathrm{NeP}$ (CDC rating $\mathrm{C}$ ). Furthermore, there are limited experiences in clinical practice with these combinations although they may work in theory, as they would attack different mechanisms of action.

\section{Combination therapy with cutaneous patches}

Apart from the combination of cutaneous patches with pregabalin/gabapentin, where there was some scientific evidence (CDC rating $\mathrm{I}+\mathrm{A} / \mathrm{C}$, Table 2 ), the Delphi panel of experts concluded that there was insufficient evidence to support a recommendation (CDC rating $\mathrm{C}$ ) for any other combination with cutaneous patches for the treatment of NeP.

However, for localized NeP, cutaneous patches should be considered because of low risk of side effects and combinations with any oral treatment is possible.

\section{Discussion}

The present Delphi panel and process has investigated the use of combination therapy in the treatment and management of $\mathrm{NeP}$ based on the available scientific evidence as well as the existing clinical practice experience. Evidence is sparse and almost exclusively within peripheral NeP conditions. As a consequence of the limited evidence within central NeP, the drugs (including drug combinations) that have proven to be efficient within peripheral $\mathrm{NeP}$ are often applied for central NeP conditions in daily clinical practice.

The combination of pregabalin/gabapentin and TCAs was the best documented and experts had good clinical experience with this combination in the management of NeP. The combination pregabalin/gabapentin and SNRI (with focus on duloxetine) was also reasonably well documented with good clinical experience and fewer side effects than high-dose monotherapy. There is also good evidence for the use of opioids in combination with pregabalin/gabapentin or TCAs. However, because of misuse and addiction issues, there are the general recommendations against opioids, which hamper the use of these drugs.

The Delphi panel also concluded that cutaneous patches can be combined with most oral therapies in patients who are suitable for local treatment.

SSRIs, on the other hand, have no role in the treatment of NeP, neither in monotherapy nor in combination therapy.

The clinical experience from the Delphi panel shows that many combinations are useful and the idea of combining drugs with different mechanisms of action may be a feasible way of providing better pain relief for the individual patient.

The importance of dose adjustments is emphasized due to the overlap of side effects and the fact that $\mathrm{NeP}$ conditions are often dynamic. Dose titration in combination therapy has been a topic of discussion. The clinical experience is almost exclusively on add-on or sequential therapy, that is, starting with, for example, a TCA and titrating to a dose that might be limited by either side effects or insufficient effect and then adding, for example, pregabalin/gabapentin in a slow titration. Another approach is simultaneous titration of the drugs to the MTD, leading to a more balanced dose ratio.

The limited scientific literature on combination therapy makes it difficult to make recommendations based on hard evidence, which is also why the Cochrane review on combination pharmacotherapy for the treatment of $\mathrm{NeP}$ in adults from 2012 concluded: "no combination treatment has sufficient evidence to be recommended in NeP", Chaparro et al. ${ }^{8}$

Overall, the level of evidence is low as it is primarily based on a low number of expert opinions and clinical experiences. However, we cover a broad spectrum of clinical practice and academia with differences in medical specialties and clinical settings. In spite of the lack of sufficient evidence, the Delphi panel reached a similar conclusion to that of a Lancet review in 2013: "Escalating efforts to develop novel analgesics that surpass the efficacy of current treatments have not yet been successful; therefore, combination therapy remains an important beneficial strategy", Gilron et al. ${ }^{26}$

\section{Conclusion}

Despite the fact that combination therapy is widely used in clinical practice with generally good results, existing guidelines on pain management do not contain much information or recommendations on combining pharmacological pain therapies to improve pain management in NeP. This Delphi process revealed that there is some scientific evidence available supporting the combinations of pharmacological pain therapies. Further studies on combination therapy are needed - also including non-pharmacological therapies, but 
the present Delphi process results add important information to the existing knowledge on combination of pharmacological pain therapies in $\mathrm{NeP}$ to be used in clinical practice and maybe in future guidelines.

\section{Acknowledgement}

Charlotte Merland - an employee of Pfizer Denmark - was a moderator of the Delphi process. Peter Bo Poulsen, PhD. - an employee of Pfizer Denmark - was a medical writer of the present article together with Ingrid Edsman from Edsman Medical Writing.

\section{Author contributions}

JVH participated and commented on the design of the study, participated in the Delphi process and drafted part of the manuscript. AJ, TJ, MW, CB and FWB commented on the design of the study, participated in the Delphi process, and commented on the manuscript. All authors contributed toward data analysis, drafting and critically revising the paper. All authors have read and approved the final version of the manuscript to be published, and are accountable for all aspects of the work in ensuring that questions related to the accuracy or integrity of any part of the work are appropriately investigated and resolved.

\section{Disclosure}

The authors report no conflicts of interest in this work.

\section{References}

1. Costigan M, Scholz J, Woolf CJ. Neuropathic Pain. A Maladaptive Response of the Nervous System to Damage. Annu Rev Neurosci. 2009;32:1-32.

2. Sundhedsstyrelsen [National Board of Health]. National klinisk retningslinje for udredning og behandling/rehabilitering af patienter med generaliserede smerter i bevægeapparatet [National Clinical Guideline for investigation and treatment/rehabilitation of patients with generalized pain in the musculoskeletal system], 2015. Available from: https:// sundhedsstyrelsen.dk/da/udgivelser/2015/ /media/C2305D647E6F4E5B9229D88E96322335.ashx. Accessed January 21, 2015.

3. Institut for Rationel Farmakoterapi [Department of Rational Pharmacotherapy]. National Rekommandationsliste for ATC-gruppe N02A, N03A og N06A - neuropatiske smerter [National Recommendation List for ATC group NO2A, NO3A and NO6A neuropathic pain]; 2011. Available from: http://www.irf.dk/dk/rekommandationsliste/baggrundsnotater/ nervesystemet_analgetika_og_psykofarmaka/atc-gruppe_n02a_n03a_ og_n06a_-_neuropati.htm. Accessed October 27, 2015.

4. Dansk Endokrinologisk Selskab [Danish Endocrinological Society]. NBV Endokrinologi: Diabetisk Neuropati [NBV Endocrinology: Diabetic neuropathy]; 2015. Available from: http://www.endocrinology. dk/index.php/1-diabetes-mellitus/5-diabetisk-neuropati. Accessed May 2015.

5. Dansk Neurologisk Selskab [Danish Neurological Society]. Neurologisk National Behandlingsvejledning. Behandling af neuropatiske smerter [Neurological National Treatment Guide. Treatment of neuropathic pains]; 2015. Available from: http://neuro.dk/wordpress/nnbv/behandling-af-neuropatiske-smerter/. Accessed December 3, 2015.
6. Attal N, Gruccu G, Baron R, et al. EFNS guidelines on the pharmacological treatment of neuropathic pain: 2010 revision. Eur J Neurol. 2010;17(9):1113-1123.

7. Finnerup NB, Attal N, Haroutounian S, et al. Pharmacotherapy for neuropathic pain in adults: a systematic review and meta-analysis. Lancet Neurol. 2015;14(2):162-173.

8. Chaparro LE, Wiffen PJ, Moore RA, Gilron I. Combination pharmacotherapy for the treatment of neuropathic pain in adults. Cochrane Database Syst Rev. 2012;7:CD008943.

9. Kish MA. IDSA Guidelines. Guide to development of practice guidelines. Clin Infect Dis. 2001;32(6):851-854.

10. Gilron I, Bailey JM, Tu D, Holden RR, Jackson AC, Houlden RL. Nortriptyline and gabapentin, alone and in combination for neuropathic pain: a double-blind, randomised controlled crossover trial. Lancet. 2009;374(9697):1252-1261.

11. Holbech JV, Bach FW, Finnerup NB, Brøsen K, Jensen TS, Sindrup SH. Imipramine and pregabalin combination for painful polyneuropathy: a randomized controlled trial. Pain. 2015;156(5):958-966.

12. Tesfaye S, Wilhelm S, Lledo A, et al. Duloxetine and pregabalin: highdose monotherapy or their combination? The "COMBO-DN study"-a multinational, randomized, double-blind, parallel-group study in patients with diabetic peripheral neuropathic pain. Pain. 2013;154(12):2616-2625.

13. Tanenberg RJ, Irving GA, Risser RC, et al. Duloxetine, pregabalin, and duloxetine plus gabapentin for diabetic peripheral neuropathic pain management in patients with inadequate pain response to gabapentin: an open-label, randomized, noninferiority comparison. Mayo Clin Proc. 2011;86(7):615-626.

14. Sindrup SH, Gram LF, Brøsen K, Eshøj O, Mogensen EF. The selective serotonin reuptake inhibitor paroxetine is effective in the treatment of diabetic neuropathy symptoms. Pain. 1990;42(2):135-144.

15. Otto M, Bach FW, Jensen TS, Brøsen K, Sindrup SH. Escitalopram in painful polyneuropathy: a randomized, placebo-controlled, cross-over trial. Pain. 2008;139(2):275-283.

16. Gilron I, Bailey JM, Tu D, Holden RR, Weaver DF, Houlden RL. Morphine, gabapentin, or their combination for neuropathic pain. $N$ Engl $J$ Med. 2005;352(13):1324-1334.

17. Hanna M, O'Brien C, Wilson MC. Prolonged-release oxycodone enhances the effects of existing gabapentin therapy in painful diabetic neuropathy patients. Eur J Pain. 2008;12(6):804-813.

18. Caraceni A, Zecca E, Bonezzi C, et al. Gabapentin for neuropathic cancer pain: a randomized controlled trial from the Gabapentin Cancer Pain Study Group. J Clin Oncol. 2004;22(14):2909-2917.

19. Casale R, Polati E, Schweiger V, Coluzzi F, Bhaskar A, Consalvo M. [Localized neuropathic pain-5\% lidocaine medicated patch as a firstline treatment and as add-on therapy: literature review and personal experience]. Minerva Med. 2014;105(3):177-195. Italian.

20. Meier T, Wasner G, Faust M, et al. Efficacy of lidocaine patch $5 \%$ in the treatment of focal peripheral neuropathic pain syndromes: a randomized, double-blind, placebo-controlled study. Pain. 2003;106(1-2):151-158.

21. Irving GA, Backonja M, Rauck R, Webster LR, Tobias J, Vanhove GF. NGX-4010, a capsaicin $8 \%$ dermal patch, administered alone or in combination with systemic neuropathic pain medications, reduces pain in patients with postherpetic neuralgia. Clin J Pain. 2012;28(2):101-107.

22. Haanpää M, Hietaharju A. Treating Herpes Zoster and Postherpetic Neuralgia. Pain Clin Updates. 2015;23(4):1-8.

23. Mercadante S, Arcuri E, Tirelli W, Villari P, Casuccio A. Amitriptyline in neuropathic cancer pain in patients on morphine therapy: a randomized placebo-controlled, double-blind, crossover study. Tumori. 2002;88(3):239-242.

24. Khoromi S, Cui L, Nackers L, Max MB. Morphine, nortriptyline and their combination vs. placebo in patients with chronic lumbar root pain. Pain. 2007;130(1-2):66-75.

25. Gilron I, Tu D, Holden RR, Jackson AC, DuMerton-Shore D. Combination of morphine with nortriptyline for neuropathic pain. Pain. 2015;156(8):1440-1448.

26. Gilron I, Jensen TS, Dickenson AH. Combination pharmacotherapy for management of chronic pain: from bench to bedside. Lancet Neurol. 2013;12(11):1084-1095. 
The Journal of Pain Research is an international, peer reviewed, open access, online journal that welcomes laboratory and clinical findings in the fields of pain research and the prevention and management of pain. Original research, reviews, symposium reports, hypothesis formation and commentaries are all considered for publication
The manuscript management system is completely online and includes a very quick and fair peer-review system, which is all easy to use. Visit http://www.dovepress.com/testimonials.php to read real quotes from published authors. 